\title{
Legere et interpretari: letramentos midiáticos como metodologia de aprendizagem
}

\author{
Legere et interpretari: media literacy as learning methodology
}

\section{Legere et interpretari: alfabetización mediática como metodología de aprendizaje}

Raquel Timponi Pereira Rodrigues | raquel.timponi@gmail.com

Universidade do Estado do Rio de Janeiro, Laboratório de Mídias Digitais PPGCOM/UERJ. Rio de Janeiro, Brasil.

Fátima Cristina Regis Martins de Oliveira | fatimaregisoliveira@gmail.com

Universidade do Estado do Rio de Janeiro, Laboratório de Mídias Digitais PPGCOM/UERJ. Rio de Janeiro, Brasil.

\section{Resumo}

Este artigo apresenta uma metodologia com base no uso de diversos letramentos midiáticos, aplicada em oficinas junto às disciplinas formais do Ensino Fundamental II. Com o objetivo de tornar o conteúdo escolar mais atrativo e contextualizado e, ao mesmo tempo, capacitar alunos e professores para o domínio da linguagem midiática, a metodologia se inspira na proposta da investigação-ação de Thiollent e aplica estratégias de afetividade e participação dos alunos na criação de produtos midiáticos (livroclipes, vídeos e jogos), cuja produção permite reinterpretar os conteúdos escolares, potencializando a sua assimilação. A oficina piloto desenvolvida em uma escola pública no estado do Rio de Janeiro comprova que a afetividade e os referenciais culturais prévios contribuem para um aprendizado mais prazeroso e contextualizado. Conclui-se que é cabível sua aplicação no currículo, de forma a promover melhor compreensão do conteúdo escolar e reflexão crítica sobre ele.

Palavras-chave: metodologia; letramentos múltiplos; oficina; aprendizagem; experiência. 


\begin{abstract}
This paper presents a methodology based on the use of various media literacies, applied in workshops integrated with formal courses of Secondary School. The goal is to make the school contents more attractive and contextualized and, at the same time, qualify students and teachers in the field of media languages. The methodology is inspired in Thiollent action research ideas and applies strategies of affectivity and student participation in creating media products (booktraillers, videos, games), whose production enables to reinterpret school contents intensifying their assimilation. The pilot project developed in a public school in the state of Rio de Janeiro (Brazil) proves that affection and previous cultural references contribute to a more pleasurable and contextualized learning. In conclusion, it is reasonable its application in the curriculum, in order to promote better understanding and critical reflection on school programs.
\end{abstract}

Keywords: methodology; multiple literacies; workshop; learning; experience.

\title{
Resumen
}

Este artículo presenta una metodología basada en el uso de diversas alfabetizaciones mediáticas, aplicada en talleres integrados a las materias de la Educación Secundaria en una escuela pública en Brasil. Con el objetivo de hacer el contenido escolar más atractivo y contextualizado y, al mismo tiempo, capacitar alumnos y profesores en el dominio del lenguage mediática, la metodología se inspira en la propuesta de la investigación-acción con aplicación de estrategias de afectividad y participación de los alumnos en la creación de productos mediáticos (libroclipes, videos, juegos), cuya producción permite reinterpretar los contenidos escolares, potencializando su asimilación. El taller piloto, desarollado en una escuela pública del estado del Río de Janeiro, Brasil, la demostración es que la afectividad y los referenciales culturales previos contribuyen para un aprendizado con más placer y contextualizado. En conclusión, es pertinente su aplicación en el plan de estudios, con el fin de promover mejor compreensión del contenido escolar y reflexión crítica sobre él.

Palabras clave: metodología; alfabetizaciones multiples; taller; aprendizage; experiencia.

INFORMAÇÕES DO ARTIGO

Contribuição dos autores: os autores são responsáveis por todo o texto.

Declaração de conflito de interesses: não houve.

Fontes de financiamento: Durante a oficina, a pesquisa contou com os financiamentos: Coordenação de Aperfeiçoamento de Pessoal de Nível Superior (Capes), Secretaria de Extensão Comunitária do Centro Universitário de Barra Mansa(UBM)/RJ e Setor Inovuerj LMD/PGGCOM/UERJ.

Considerações éticas: não há.

Agradecimento/Contribuições adicionais: não há.

Histórico do artigo: Submetido: 29.abr.2016 | Aceito: 03.out.2017 | Publicado: 29.dez.2017

Apresentação anterior: não houve.

Licença CC BY-NC atribuição não comercial. Com essa licença é permitido acessar, baixar (download), copiar, imprimir, compartilhar, reutilizar e distribuir os artigos, desde que para uso não comercial e com a citação da fonte, conferindo os devidos créditos de autoria e menção à Reciis. Nesses casos, nenhuma permissão é necessária por parte dos autores ou dos editores. 


\section{Introdução}

A erradicação do analfabetismo no Brasil é um desafio. Nas últimas décadas, o país conseguiu reduzir substancialmente seus índices estatísticos relativos a essa questão. Porém, quando se avalia os estudantes por meio de abordagens qualitativas, observa-se o analfabetismo funcional como um novo problema. O estudante aprende a ler e escrever, mas não compreende o que lê, e não desenvolve competências para distinguir diferentes tipos de textos e linguagens.

Um dos principais desafios a ser superado é o método de ensino oficial brasileiro que se baseia em uma pedagogia de transmissão de conhecimentos. Frequentemente, os conteúdos educativos não têm aplicabilidade e são desinteressantes para os jovens, habituados ao uso de tecnologias atraentes, como celulares, computadores e videogames. É nesse panorama de ausência de escuta no contato com a mensagem, no caso, o conteúdo escolar tradicional, que o debate sobre a alfabetização midiática ganha importância. Torna-se fundamental criar metodologias de ensino que tornem o conteúdo escolar mais contextualizado e atrativo, de forma a gerar um aprendizado conectado à vida e cultura do aluno.

Podemos sintetizar duas faces desse desafio. Por umlado, o currículo oficial unificadoédescontextualizado, não considera as diversidades culturais e geográficas do país; e a pedagogia tradicional, pautada no modelo transmissionista, apresenta métodos e conteúdos não aplicáveis na vida e na experiência prévia dos alunos, além de não estimularem a sua reflexão crítica. Por outro lado, também é preciso relativizar. Os produtos da comunicação digital utilizam recursos como sons, fotos, vídeos, músicas e aplicativos táteis, que, embora sedutores, frequentemente possuem baixo teor conteudístico e os quais os alunos não estão preparados para assimilar de forma crítica. Soma-se à essas considerações a questão cultural de que alguns produtos tecnológicos de leitura em áudio, apesar do potencial, não possuem habitualmente um grande público para a escuta. Em busca de uma proposta que abranja as duas faces dessa problemática, este artigo apresenta uma metodologia que aplica as linguagens midiáticas ao conteúdo de disciplinas da educação formal em escolas públicas do Rio de Janeiro. Essa metodologia faz parte das pesquisas realizadas pelo Laboratório de Mídias Digitais (LMD), um laboratório de ensino, pesquisa e extensão, vinculado ao Programa de Pós-Graduação em Comunicação da Uerj, e, ao mesmo tempo, reúne os resultados da tese de doutorado ${ }^{1}$ de uma das pesquisadoras do laboratório. A metodologia aplica estratégias de afetividade e de incentivo à participação do aluno na criação de produtos midiáticos (livroclipes, vídeos e jogos) cuja produção permite criar e reinterpretar os conteúdos escolares, potencializando a sua assimilação. O objetivo é tornar o conteúdo escolar mais atrativo e contextualizado e, ao mesmo tempo, capacitar alunos e professores para o domínio das linguagens midiáticas de modo que, pelo interesse, consequentemente raciocinem e desenvolvam visão crítica de seus conteúdos.

O artigo está estruturado em quatro seções. Na primeira, explicamos a temática e a base teórica que fundamentam a metodologia de ensino proposta. Na segunda seção, apresentamos a metodologia de uma oficina já realizada. Na terceira, demonstramos os resultados alcançados e, na quarta e última parte, refletimos sobre o que aprendemos com essa experiência e introduzimos as próximas oficinas que realizaremos em uma outra escola pública da rede municipal oficial de Ensino Fundamental II na cidade do Rio de Janeiro, RJ.

\section{Temática e princípios teóricos}

O LMD investiga, desde 2007, quais habilidades e competências cognitivas são estimuladas no processo de fruição de produtos midiáticos por jovens e crianças. O LMD já analisou seriados de TV, filmes, videogames e histórias em quadrinhos produzidos desde a década de 1980 à atualidade, para compreender como os hibridismos entre linguagens (orais, impressas, audiovisuais) e o compartilhamento de informações 
potencializado pelas mídias e redes digitais podem estimular o desenvolvimento de habilidades cognitivas nos jovens. Após alguns anos de mapeamento do campo e de análises de diferentes objetos de estudo, as pesquisas concluíram que as mídias digitais e os produtos de entretenimento estimulam o desenvolvimento cognitivo dos usuários em cinco categorias de habilidades: linguísticas, lógicas, sensório-motoras, sociais e criativas.

Com base nessas pesquisas, o desafio que se apresentou aos pesquisadores do LMD foi o de como utilizar os recursos atrativos das linguagens midiáticas como forma de estimular o interesse do aluno em atividades do ensino formal. A aposta da pesquisa é adotar estratégias de incentivo à participação do aluno na produção de produtos midiáticos que se baseiem em suas vivências, de modo a facilitar o processo de aprendizado e o desenvolvimento do raciocínio crítico.

Essa proposta se alinha com ideias precursoras, como a pedagogia para a liberdade de Paulo Freire ${ }^{2}$, o sociointeracionismo de Lev Vygotsky ${ }^{3}$ e a pesquisa-ação de Michel Thiollent ${ }^{4}$, entre outras, que têm defendido a importância do contexto cultural e da vivência como determinantes do sucesso do aprendizado.

Uma inspiração recente da obra do pesquisador brasileiro Muniz Sodré 5 defende que são elementos essenciais para a compreensão das diversas formas de leitura a prática e o vínculo, estabelecidos com o objeto que se aborda, somados à interação com os outros pares e com o mundo. Dito de outro modo, o autor acredita que o processo de aprendizagem parte de referenciais de nossas vidas, como a consciência viva do grupo, os vínculos sociais e a experiência da vida prática. "A autorrepresentação e reelaboração afetiva do vivido são elementos importantes para a fixação do aprendizado pelo processo criativo independente e não somente pelo eco da voz do outro ou pela reprodução dos saberes”.

Importa ressaltar a ideia do pesquisador de que a leitura dos textos das mídias digitais favorece a ação de "implicar" 0 leitor no processo, de dar sentido à leitura:

Esses novos artefatos [as mídias digitais], de algum modo, ampliam a gestualidade do indivíduo no ato de ler. É forçoso acentuar que apenas "ampliam", uma vez que, além da produção do sentido por parte do autor e do leitor, portanto, além da dimensão semântica, algumas das técnicas editoriais do impresso (títulos, sumários, índices) sempre foram implicativas (mais do que explicativas), no sentido de que induzem e coordenam o ato de ler, dando margem à participação ativa do leitor no manuseio das páginas. Em latim explicare, significa propriamente desdobrar, estender. De dentro para fora, a partir de uma dada estrutura, amplia-se o texto por desdobramento lógico, com vistas ao desvelamento do sentido e do entendimento por parte do outro. Já implicare, ao contrário, é dobrar de fora para dentro, portanto, envolve o interlocutor, de modo a levá-lo a participar da produção do sentido ${ }^{6}$.

A dimensão explicativa atua sob o ponto de vista vertical, com o auxílio do sentido definidor do livro, característico da leitura tradicional. Nesse aspecto, é válido ponderar que o leitor nunca é passivo. Ainda que não seja demandado a participar, ainda é um ator no processo comunicacional. A dimensão implicativa envolve uma forma ativa de compreensão do interlocutor, de modo a levá-lo a participar da produção de sentido, convocando-o a ser parte produtiva da escrita.

Como Sodré destaca, se antes a dimensão implicativa do texto estava limitada a recursos complementares (ilustrações, índices, remissões), nas mídias digitais amplia-se para outras possibilidades de leitura, uma vez que interpretar significa penetrar de fato na dimensão do sentido e admite outros modos operativos de tratamento da escrita e leitura, coordenando horizontalmente as diferentes superfícies ou suportes capazes de ancorar textos, guiadas pela livre circulação da informação ${ }^{6}$. A mídia digital dá maior abertura para que o leitor se torne produtor, coautor da obra.

Por esse viés, é preciso ultrapassar o momento do legere (que significa somente recolher signos em sua ordem sequencial, para finalmente lhes atribuir um sentido e, portanto, decodificar), e adotar a perspectiva que se pretende seguir neste trabalho, que é a do interpretari (depende de uma amplitude de sentido latente e significa ler compreensivamente). O interpretari inclui o agir e define a compreensão como potência de traduzir e produzir espírito crítico. As mídias digitais demandam novos modos de ler, 
na releitura de obras com recursos implicativos, que utilizam áudio, vídeo e design e o próprio leitor que participa interativamente da escrita.

Essas pesquisas se alinham com os resultados das investigações do LMD, conforme discutimos em outro texto: "os produtos da comunicação digital utilizam sons, fotos, vídeos, músicas, software de touch screen, luzes, vibrações que exploram a riqueza de nosso sensorium, gerando experiências lúdicas, aprazíveis e contextualizadas que favorecem a atenção, percepção e o aprendizado" 7 .

As mídias digitais, por fazerem uso de recursos sensoriais sonoros, imagéticos e táteis, potencializam a atuação corporal do indivíduo. A participação corporal favorece o envolvimento emocional do aluno no processo de aprendizado, pelo afeto, tornando naturalmente o conteúdo mais atrativo para o contexto desse ator.

Esse foco da teoria do aprendizado pelas afetividades segue a vertente de pensamento de Lev Vygotsky que defende que "um fato impregnado de emoção é recordado de forma mais sólida, firme e prolongada do que um feito indiferente [como o simples costume de ler sem entender o sentido de um texto]”3.

Por esses motivos, a metodologia aqui proposta incentiva o aluno a produzir uma adaptação de uma obra literária ou outro conteúdo, passando da condição confinada de leitor a coprodutor da história, na medida em que escreve um roteiro em releitura da obra, realiza gravações em vídeo, participa como ator, colocando parte da sua imaginação na reinterpretação da obra, sua cultura e os seus referenciais midiáticos como formas de ressignificar o texto. Esse processo favorece o desenvolvimento de habilidades criativas, linguísticas, lógicas, sensório-motoras e sociais.

A metodologia se alinha também com o conceito de 'redescrições', nos termos do educador Richard Rorty, ou seja, “a capacidade de recontar as histórias em que os indivíduos estão inseridos, de maneira que eles possam se perceber como participantes na construção da história coletiva e, consequentemente, possam se qualificar como membros da comunidade atual, resultantes desse processo histórico"8.

Assim, qualquer usuário da rede pode ser um potencial produtor midiático e pode "redescrever" ou "reinterpretar", elaborando novos horizontes do conhecimento e reequilibrando a consciência do interlocutor e a sua relação com o outro nas trocas comunicativas. Reinterpretar significa realizar a 'tradução' das diversas formas de leitura e letramento de mídias diferentes, não por uma fórmula fixa transplantada, mas por uma conversão do texto em um processo comunicativo para uma atividade ou um novo texto, segundo referências próprias.

\section{Materiais e métodos aplicados na oficina piloto}

A Oficina de Produção de Livroclipes foi realizada com uma turma de 35 alunos do $9^{\circ}$ ano do Ensino Fundamental II ${ }^{\mathrm{i}}$, e aplicada em uma escola pública, o Colégio Estadual Barão de Aiuruoca, na cidade de Barra Mansa, estado do Rio de Janeiro. A oficina foi realizada como parte das atividades curriculares da disciplina de 'Produção de textos'. Para favorecer o aproveitamento, a oficina foi a avaliação oficial do bimestre escolar. A proposta de trabalho foi orientada pela pesquisadora proponente da oficina, Raquel Timponi, juntamente com a professora da disciplina Janice de Paula, durante o primeiro semestre de 2014, entre os meses de maio e setembro daquele ano. A atividade ocorreu em 10 encontros de duas horas/aula, sendo a primeira parte em sala de aula no Colégio Estadual Barão de Aiuruoca, em horário de aula, e a segunda fase de produção realizada em parceria com o Centro Universitário de Barra Mansa (UBM) que

\footnotetext{
i A faixa etária de 14 anos, escolhida para a realização da oficina teste, justifica-se por ser um período em que os alunos já possuem conhecimento prévio de lidar com as mídias digitais e ainda possuem horário livre, pois não estão totalmente dedicados ao exame de ingresso no ensino superior.
} 
cedeu o Laboratório de Multimeios do curso de Jornalismo do UBM, para a gravação ${ }^{i i}$ nos estúdios de TV e ilhas de áudio e de edição no campus dessa instituição.

O critério de escolha da turma ocorreu em função de ser híbrida, com alguns alunos de difícil aprendizado que, por serem dispersos, tinham dificuldade de concentração nas tarefas escolares. Já outros, ao contrário, eram interessados e aplicados na escola, e havia também um grupo criativo que se envolvia em projetos de teatro, o que revela um perfil variado de alunos. Considerando o perfil geral do total de participantes, 17 se revelaram com o hábito sistemático de leituras variadas (68\%) ${ }^{i i i}$, enquanto oito alunos (32\%) declararam que não gostam de ler.

Como metodologia de aplicação adotada na oficina, decidiu-se que a pesquisadora não realizaria a interferência direta na maneira de ministrar o curso, em uma linha contrária às metodologias tradicionais de ensino. Essa escolha foi proposital, para incentivar um aprendizado exploratório dos alunos e provocar ações mais espontâneas nos resultados.

Mais especificamente, com o intuito de introduzir os alunos do Ensino Fundamental no universo da produção midiática, a atividade-fim pretendeu despertar a curiosidade dos jovens pelos contos literários e promover seu envolvimento, pela prática. A aplicação da oficina ocorreu de maneira mais livre, fundamentada nos princípios do afeto e inspirada na abordagem educativa de Paulo Freire ${ }^{2}$, em uma estratégia que dá liberdade ao aluno no processo de aprendizagem e na descoberta de novas informações, abrindo espaço para a produção a partir de suas referências da cultura local e sua visão de mundo na interpretação das obras. A função do professor neste método é de atuar como um 'filtro confiável' entre as atividades, incentivando o aluno a buscar informações e a se aprofundar em assuntos por descobertas próprias (consultas a sites, pesquisas na biblioteca do colégio, adquirindo habilidades pela prática), de forma a realizar redescrições pelos elementos de seu contexto cultural. Na ausência da presença do professor, o limite da proposta dos letramentos mediáticos seria o risco de o autodidatismo levar o aluno a perder o foco principal, o objetivo da atividade, considerando apenas o processo de busca de conteúdos e o uso indiscriminado das mídias digitais.

\section{Resultados alcançados na oficina piloto}

Dos 35 alunos da turma do $9^{\circ}$ ano, 25 realizaram o trabalho até o fim e dez desistiram durante a realização do projeto. Como resultado, foram produzidos e gravados cinco contos adaptados em livroclipes: 'Reunião de mães', de Fernando Sabino; 'Diga não às drogas' (conto apócrifo); 'Uns braços', de Machado de Assis; 'O que pediria ao Diabo', de Luís Fernando Veríssimo; e 'Um apólogo', de Machado de Assis. A escolha dos contos a serem adaptados era livre e o professor não determinou livros clássicos.

Como resultados encontrados durante a atividade, cabe destacar: 1) observou-se o desconhecimento do conteúdo da disciplina de produção textual, do significado do que é uma metáfora, por exemplo, por parte dos alunos, 2) a falta de letramento midiático/digital na realização das atividades da oficina, 3) o referencial cultural e a experiência prévia como fatores determinantes no envolvimento da equipe.

Após as gravações, os produtos da oficina foram exibidos na $2^{\mathrm{a}}$ Mostra de Livroclipes, que ocorreu no Cine Show, cinema do Shopping Frigorelli de Barra Mansa. A exibição dos produtos no cinema ${ }^{\text {iv }}$ ocorreu

ii Como forma de viabilizar as gravações os grupos foram divididos em dois dias de gravação, sendo três delas realizadas no primeiro dia e duas na semana seguinte. Para que os três grupos de alunos do colégio pudessem realizar, em um mesmo dia, a gravação de imagens, locução em off no estúdio de áudio, bem como coleta de material de trilha sonora, sonoplastia, letreiro e imagens da Internet para a composição do trailer, as atividades foram realizadas simultaneamente, em rodízio.

iii Apesar de 68\% dos estudantes declararem que possuem hábito de ler, trata-se de leitura de textos diversos, não associados aos conteúdos escolares e que, por essa razão, não convergem diretamente para a melhor compreensão dos conteúdos formais. Assim, o hábito de leitura acontece de modo dissociado ao desenvolvimento de habilidades e competências necessárias ao aprendizado escolar.

iv A exibição no cinema foi possibilitada por uma parceria com o Cine Show do Shopping Frigorelli de Barra Mansa e os custos pagos pelo projeto de extensão para Oficinas de Livroclip, pela Secretaria de Extensão Comunitária do UBM, em que a pesquisadora era docente, em parceria com o Colégio de Aplicação, aprovada no início do ano. 
em setembro de 2014 e todos os participantes da turma ganharam ingressos extensivos aos familiares para assistirem aos trailers de livro, exibidos no cinema local, com direito à pipoca e troféu de participação.

A professora oficial da disciplina, Janice de Paula, avaliou o resultado da oficina, em uma entrevista publicada no programa Giro Acadêmico, da Rádio UBM, relativa aos resultados do projeto aplicado, destacando que o projeto agregou à disciplina de Produção de Texto:

O projeto ofereceu aos alunos a oportunidade de uma aprendizagem mais aprofundada. Tendo em vista que o assunto a ser trabalhado em sala de aula no semestre eram os contos e crônicas, a prática da oficina os auxiliou no processo de fixação do conteúdo e aprendizado, por meio de suas experiências pessoais ${ }^{\mathrm{v}}$.

Após a exibição no cinema, de volta à escola, em entrevista com os componentes dos grupos, alguns participantes afirmaram que se interessaram em ler outras obras do autor que trabalharam (como no caso de uma aluna que começou a ler 'Dom Casmurro', após a adaptação de 'Uns braços', de Machado de Assis) ou de outros autores que conheceram novas obras instigados pelos livroclipes produzidos pelos demais colegas.

\title{
Discussão
}

Como debate dos resultados, é importante analisar os três elementos enumerados no tópico anterior. O primeiro que merece destaque é a falta de conhecimento do conteúdo escolar por parte dos alunos, que surgiu logo no primeiro encontro. Após uma conversa introdutória, para captar o conhecimento prévio sobre os autores brasileiros e hábitos de leitura, parte da turma não conhecia o produto livroclip (trailer de livro), o que se diferenciou de outra turma da rede particular que já tinha contato com o produto e que teve maior facilidade de abordagem da linguagem. Durante uma das instruções, a turma tampouco sabia o que era metáfora, conceito que seria utilizado na oficina para adaptar um texto impresso para a linguagem do audiovisual, o que demandou esclarecimento por parte da pesquisadora, tal como o trecho do relato etnográfico registrado em campo:

\begin{abstract}
No primeiro encontro com a turma, os alunos não conheciam ou tinham ouvido falar de booktrailer ou livroclip. [...] Em relação às obras brasileiras, enquanto a pesquisadora apresentava as propostas estéticas de trailers de livro, especificamente da adaptação de 'Dom Casmurro', de Machado de Assis, os alunos não conheciam um dos autores mais comentados da literatura no Brasil, assim como não sabiam o que era metáfora, conceito que seria utilizado na atividade da oficina, como forma de buscar elementos para representação do texto impresso para a adaptação em audiovisual (Relato etnográfico realizado pela pesquisadora, registrado no dia 08 de maio de 2014) ${ }^{\text {vi }}$.
\end{abstract}

O segundo elemento observado durante a aplicação da oficina foi a falta de domínio no processo de busca de informações pelo aluno, que traz o debate da questão do livre aprendizado, bem como o questionamento sobre a veracidade das informações disponíveis na rede, e exige um letramento digital mais aprofundado para a seleção de dados. O problema foi identificado logo após a divisão da turma em equipes, ainda no processo de escolha do conto a ser adaptado. Um grupo de alunos trouxe um conto apócrifo, fruto da pesquisa realizada em casa, que constava em sites correntes da literatura na internet como de autoria de Luís Fernando Veríssimo (apesar de ser um conto sem autoria conhecida).

$\mathrm{O}$ evento relatado elenca alguns assuntos importantes referentes à autenticidade da obra e à busca confiável na internet. O equívoco dos alunos, provocado pela busca aleatória na rede, trouxe um debate relacionado aos riscos das fontes de consulta não licenciadas, bem como um alerta para os problemas da

v Entrevista concedida ao programa Giro Acadêmico da Radio UBM, no dia no dia 17 de setembro de 2014.

vi Todas as citações extraídas dos relatos etnográfico encontram-se na tese de doutorado da autora, Timponi ${ }^{1}$. 
informação inverídica propagada, quando não se sabe a origem do conteúdo. Apesar de os alunos terem sido orientados a trazerem material de livros impressos, o fato de não haver naquele momento acesso disponível à internet para a checagem fez com que o conto fosse adaptado, além de relatar a falta de expertise dos alunos quando optaram por realizar buscas sem a preocupação com a confiabilidade da informação acessada.

Sobre a questão do risco da propagação da informação da internet e de seu acesso pela rede, o autor Luís Fernando Veríssimo se pronunciou sobre o texto na rede considerado de sua autoria, em um artigo escrito no site do Jornal O Estado de S. Paulo (Estadão), em 18 de janeiro de 2002, denominado'Veríssimos inverossímeis:

Apócrifos: Não sei se existem outros, mas há pelo menos dois textos rolando pela internet com a minha assinatura dos quais sou inocente. [...] Que fique estabelecido, portanto, que qualquer texto mal escrito, ou bem escrito, mas controvertido, ou incoerente, bobo, nada a ver, pretensioso, metido a besta, pseudolírico, pseudoqualquer coisa, [...] com a minha assinatura, na internet ou fora dela, não é meu. [.... ${ }^{10}$.

Ainda como resultado referente às habilidades e aos conteúdos exercitados, imaginava-se que os alunos desenvolveriam competências na seleção de informações do texto para a redação do roteiro ${ }^{\text {vii. }}$. As atividades exigiam noções dos elementos da narrativa que compõem o texto, como enredo, sinopse, papel dos personagens principais, conflito, clímax e desfecho da trama. Dessa forma, os alunos também desenvolveriam habilidades no manuseio das mídias digitais, como a capacidade de seleção de informações na rede, descrição dos personagens principais e suas características, saberiam extrair trechos de suas falas para a adaptação, exercitariam a capacidade de resumo, além da interpretação e construção intertextual, por meio de suas referências culturais prévias, reutilizadas em cenas, sons e nos modos de representação imagética (metafórica) para a tradução da linguagem do texto impresso para o audiovisual. Esperava-se que a representação do conto como atores, aproximaria a trama de seu universo pela experiência, por sua contribuição pessoal à narrativa.

Todavia, apesar de se supor que os alunos de uma geração de nativos digitais teriam facilidade no manuseio das mídias digitais, o contexto sociocultural do público analisado foi um pouco diferente do que se esperava e interferiu nas atividades que exigiam um domínio da tecnologia, conforme revelou a ‘observação participante’ da pesquisadora:

Durante a realização da fase de pesquisas sobre o autor e obra, alguns alunos apresentaram dificuldades, pois não sabiam como pesquisar na rede, que tipo de seleção da informação trariam para o trabalho, ou de qual site poderiam extrair a informação. Outros se dispersavam na rede, [...]. Alguns possuíam dificuldades de operar os computadores da escola, que eram software livres em uma lógica de funcionamento diferente do sistema operacional Windows. [...] Com relação à seleção de informações, por não possuírem um domínio da linguagem midiática dos roteiros, apesar da orientação da pesquisadora de buscarem informações curtas, de no máximo cinco linhas, por vezes selecionavam textos muito grandes, não sabiam que tipo de informação era importante colocar sobre o autor, ou redigiam outros textos com linguagem inadequada, o que demonstra a falta de prática com a linguagem escrita e de um letramento digitalviii.

Esse relato retoma a questão central do 'letramento midiático' já abordado pela Unesco ${ }^{11}$ e das habilidades requeridas para operar a mídia, em que é importante saber qual informação selecionar, bem como se posicionar de forma crítica sobre o conteúdo, utilizando a criatividade, interpretando e reutilizando linguagens com novas funcionalidades, o que poderia ser utilizado na adaptação para o trailer de livro e

vii Como os alunos não conheciam a linguagem técnica de enquadramentos do audiovisual, utilizada em roteiros, foi pedido que eles descrevessem como as imagens entrariam na tela (de longe, em uma paisagem externa ou, de perto, em detalhe do rosto, etc.). O objetivo não era torná-los técnicos, mas desenvolver habilidades de lidar com o texto e a redação, como parte do conteúdo da disciplina de Produção Textual embutido na atividade prática. 
que corrobora a perspectiva da autonomia crítica da redescrição. Porém, como os alunos ainda estavam iniciando o contato com essa experiência, a professora, a pesquisadora e a estagiária atuaram como filtros confiáveis, orientando o processo da busca e descoberta das informações para serem utilizadas no roteiro.

$\mathrm{O}$ terceiro elemento que merece destaque e que foi determinante no envolvimento das equipes foi o referencial cultural e a experiência prévia dos alunos. Durante as gravações realizadas nos estúdios de áudio e TV e nas dependências do campus da faculdade da UBM, especialmente nas gravações dos livroclip 'Um Apólogo' e 'O que eu pediria ao Diabo', o contato prévio de duas estudantes com a obra e com atividades extraclasse, como o teatro, contagiou toda a equipe durante o processo de realização. Como perfil, o primeiro grupo era de alunas que já haviam feito escolinha de teatro e se dispuseram a encenar, gravar vozes, o que gerou um resultado positivo, pois se reconheceram como parte da adaptação, promovida pela experiência.

Porém, no que se refere ao processo de gravação do áudio em off, embora as alunas tenham separado corretamente as falas dos personagens e dividido falas para a narração no estúdio de áudio (o que demonstra entendimento do contexto da história), no momento da narração, como alguns trechos do roteiro foram redigidos em português antigo (referente ao conto), as alunas apresentaram dificuldade na compreensão e na leitura e, muitas vezes, reproduziam as falas pela sonoridade, sem entenderem o contexto, transmitindo ao ouvinte a impressão de uma leitura sem clareza e interpretação, impedindo o entendimento pleno da mensagem. Em entrevista concedida após a apresentação do conto, as alunas comentaram sobre a dificuldade da leitura que enfrentaram:

Quando fomos gravar o áudio do roteiro, primeiro achamos que seria fácil. Mas não é
simplesmente chegar e falar. O locutor precisa ler com calma todas as palavras. [...] A gente
não estava acostumada a pronunciar aquelas palavras do autor, que utilizava um texto
original, um português antigo que não falamos no cotidiano. Mas como já fizemos teatro,
isso ajuda a representar. Regravamos o off diversas vezes, sob orientação da estagiária
de Letras, buscando dar maior entonação e trazer entendimento ao texto. O mais legal é
que o pessoal da turma reconheceu nossas vozes no momento da exibição no cinema e foi
engraçado. As pessoas riam no cinema. ${ }^{\text {ix }}$

Voltando ao engajamento contagiante gerado na equipe, quando um dos participantes já realizava atividades artísticas extraclasse, esse processo também pôde ser observado no momento da gravação do livroclip 'O que pediria ao Diabo', uma adaptação do conto de Luis Fernando Veríssimo, do livro 'Comédias da vida privada'. A interpretação mais livre do conto e a criatividade dos alunos apareceu desde o início da realização do roteiro. Como resultado, foi realizada uma releitura do conto, readaptando a linguagem antes de humor para terror e suspense, demonstrando domínio da trama.

Além disso, o aluno que representou o personagem do diabo se envolveu, ensaiou possíveis interpretações para a voz do personagem do conto em casa, o que foi revelado em entrevista realizada à pesquisadora:

Fazer o livroclip demandou estudo. O livro abriu uma porta para nós. [...] Foi bastante interessante, pois nunca tinha entrado em um estúdio de gravação. Não tive dificuldade com a representação do personagem na hora da gravação, pois já faço teatro no Sesc aqui de Barra Mansa, então já estou apto a incorporar personagens, tenho facilidade quanto a isso. [...] Para criar o personagem ensaiei, tive que me aprofundar bastante. Como o meu personagem era o 'diabo' e não queria que ganhasse o tom cômico, preferi o trágico. Fui para as gravações com as falas mais ou menos na memória [em referência à prática comum do teatro de decorar falas]

Assim, os demais alunos do grupo também pensaram em criar uma ambiência durante a gravação, escolheram uma trilha sonora de suspense, produziram efeitos visuais na câmera, souberam lidar com o improviso e a criatividade ao preferirem gravar de última hora na mata do campus do UBM, demonstrando

ix Trecho da entrevista concedida à pesquisadora.

x Entrevista realizada no dia 17 de setembro de 2014, após apresentação com os alunos que realizaram a produção 'O que eu pediria ao Diabo'. 
facilidade de alternar os cenários, o que resultou em um produto bem executado. Foram feitos testes de maquiagem para a composição dos personagens e um dos grupos optou pela alteração das vozes dos alunos no estúdio de áudio, objetivando engrossar o timbre do personagem principal, para transmitir um efeito do sobrenatural, elementos que incrementaram o enredo do conto.

\section{Considerações finais}

Comprovou-se, pela oficina produzida, que o envolvimento e a afetividade são gerados pela experiência prática e, ao mesmo tempo, lúdica, gerando um aprendizado prazeroso e contextualizado. Observou-se ainda que, apesar da dificuldade da turma de escola pública no manuseio das mídias digitais, habilidades no contato com o texto foram refinadas, gerando a criação de novas ideias, o desenvolvimento de linguagens e a consequente fixação do conteúdo.

Após a realização da oficina piloto, o LMD desenvolveu em 2015 um plano metodológico para a aplicação de um projeto pedagógico nas escolas públicas do estado do Rio de Janeiro. Para enriquecer o currículo escolar, o método consiste na realização de oficinas e projetos em que, por meio de desafios e tópicos, o conteúdo da disciplina é gradualmente apreendido, como forma de buscar um aprendizado mais natural e lúdico. Em resposta ao sistema escolar obsoleto e aos desafios do ensino no mundo contemporâneo, essa proposta inovadora de ensino conduz à formação de alunos intuitivos, curiosos, capazes de aprender, de tomar decisões e de trabalhar em equipe, uma vez que incentiva o aprendizado colaborativo nas trocas em grupo e o conhecimento gerado no desenvolmento da criatividade e na ampliação do repertório cultural dos grupos.

O objetivo é buscar formação de estudantes, incentivando o conhecimento gerado por habilidades desenvolvidas através do uso das mídias digitais nas atividades propostas. Essas mídias têm como característica intrínseca a associação de múltiplas linguagens (orais, audiovisuais, escritas, musicais e outras) e, consequentemente, sensibilizam mais sentidos corporais nas práticas de comunicação e aprendizagem. Ao estimular a sensorialidade e expressão corporal do estudante, as mídias digitais favorecem a aprendizagem pela interação com o grupo, estimulando processos afetivos em situações concretas e contextualizadas, oriundos das técnicas de encenação clássica. Como as mídias são próximas do cotidiano dos alunos, podem ser empregadas para um uso consciente, fazendo com que os estudantes aprendam por meio de ideias estimulantes, visando exercitar competências de diferentes áreas do saber, em uma perspectiva integrada de ensino. Os módulos são desenvolvidos no plano de ensino com sequências didáticas que determinam papéis específicos do aluno na construção do projeto, e o conteúdo da disciplina é desenvolvido. Os desafios propostos instigam o aluno a prosseguir na atividade pela curiosidade e fazem com que se integre a partir de seu contexto sociocultural, o que contribuirá para o aprendizado por sua vivência em ações planejadas em sintonia com as demandas coletivas e individuais.

Quando redigimos este artigo, já havíamos planejado uma oficina do LMD, com início em abril de 2016, a ser realizada com os alunos do $8^{\circ}$ ano do E. F. II da Escola Municipal Madrid, da rede pública do Rio de Janeiro, em uma turma com dificuldade de aprendizado. Para a consolidação dessa proposta serão realizadas uma oficina de jogo de realidade alternada sobre a temática das Olimpíadas Rio 2016 e também outra oficina sobre projetos de colaboração na rede.

Ainda como considerações finais, é válido dizer que a oficina piloto demonstrou a importância do repertório cultural prévio do aluno, da experiência de vida para a seleção do conto, elementos fundamentais para a promoção do engajamento, a apropriação bem realizada e o sucesso no desenvolvimento de linguagens e aprendizado.

Diferentes habilidades no uso das mídias digitais foram exercitadas e serão úteis no desenvolvimento de novas formas de metodologias de ensino que integram o uso das mídias digitais ao conteúdo em sala de 
aula. O intuito é de que essa metodologia seja apropriada pela rede pública de ensino e, mais tarde, ganhe abrangência no estado do Rio de Janeiro.

Posteriormente, ainda constam no plano de trabalho, o envio de uma proposta de reformulação das diretrizes curriculares do MEC à comissão da Unesco que avalia as políticas de educação no país, como exemplo de um estudo de caso de educação midiática, aplicada no estado do Rio de Janeiro.

\section{Referências}

1. Rodrigues RTP. Modos de leitura do jovem brasileiro contemporâneo: um estudo dos audiolivros e dos livroclipes [tese]. Rio de Janeiro: Universidade Federal do Rio de Janeiro; 2015 [citado 2017 jul. 22]. Disponível em: http://objdig.ufrj.br/30/teses/831476.pdf

2. $\quad$ Freire P. Educação como prática de liberdade. Rio Janeiro: Paz e Terra; 1967.

3. Vygotsky LS. A educação do comportamento emocional. In: Vygotsky LS. Psicologia pedagógica: edição comentada. Porto Alegre: Artmed; 2003:113-124.

4. Thiollent M. Metodologia da pesquisa-ação. São Paulo: Cortez; 1998.

5. Sodré M. Ciência e método em comunicação. In: Lopes MIV, organizadora. Epistemologia da Comunicação. São Paulo: Loyola; 2003.

6. Sodré M. Reinventando a educação: diversidade, descolonização e redes. Petrópolis: Vozes; 2012.

7. Regis F. Textos, texturas e intertextos: apontamentos sobre aprendizado e competência na comunicação digital. Intexto. 2015;33(1):209-24.

8. Rorty R. A filosofia e o espelho da natureza. Rio de Janeiro: Relume Dumará; 2011.

9. Vattimo G. Nichilismo ed emancipazione: etica, política, diritto. Milão: Garzanti Libri; 2003.

10. Veríssimo LF. Veríssimos inverossímeis. O Estado de S. Paulo (Grupo Estado). 2002 jan. 18 [citado 2014 out. 13]. Disponível em: www.estado.estadao.com.br/editorias/2002/01/18/pol005. html

11. Grizzle A, Moore P, Dezuanni M, Asthana S, Wilson C, Banda F, et al. Media and information literacy: policy and strategy guidelines. Paris: Unesco; 2013. 